\title{
Salivary Amylase in Cystic Fibrosis: A Marker of Disordered Autonomic Function
}

\author{
GEOFFREY P. DAVIDSON, ALY KOHEIL, AND GORDON G. FORSTNER ${ }^{(2 \pi)}$ \\ Kinsmen Cystic Fibrosis Research Center, The Hospital for Sick Children, Toronto, Ontario, Canada
}

\begin{abstract}
Summary
Total serum amylase was determined in 83 patients with cystic fibrosis (CF) (14 of whom had no steatorrhea), 21 control patients, and 6 patients with Shwachman's syndrome. Patients with $C F$ who had steatorrhea and therefore lacked pancreatic function had the same serum levels pre- and postprandially as the control subjects, whereas patients without steatorrhea and, therefore, with evidence of pancreatic function, had significantly higher levels. The patients with Shwachman's syndrome had significantly lower total serum amylase than the three other patient groups. Only the patients with Shwachman's syndrome demonstrated a significant postprandial rise in activity. Only the salivary isoenzyme was detected in patients with Shwachman's syndrome or CF and apparently absent pancreatic function, whereas CF patients without steatorrhea had both salivary and pancreatic isoenzymes. These results demonstrate that patients with CF have an increase in circulating salivary amylase isoenzyme whereas patients with Shwachman's syndrome do not. The increase probably reflects an autonomic hyperstimulation of salivary secretion which is primary to $\mathrm{CF}$, and unrelated to the state of pancreatic activity.
\end{abstract}

\section{Speculation}

We speculate that high serum salivary amylase isoenzyme levels are the result of a disordered secretory stimulus operating in $\mathrm{CF}$ which probably affects multiple organs and causes many of the manifestations of the disease.

Patients with $\mathrm{CF}$ have been reported to have normal serum amylase values $(13,22)$ in spite of the lack of pancreatic activity. This suggested to us that an increased salivary isoenzyme activity might be present in this disease. In order to explore this possibility total serum amylase and isoenzyme patterns from a series of patients were studied, including CF patients with and without steatorrhea, patients with exocrine pancreatic insufficiency without CF (Shwachman's syndrome), and a control group who had neither CF nor pancreatic insufficiency. Patients were studied in the fasting and postprandial state to see whether any differences in amylase activity might be amplified by provocation (21).

\section{PATIENTS AND METHODS}

Eighty-three outpatients with $\mathrm{CF}$ attending the $\mathrm{CF}$ clinic at The Hospital for Sick Children were selected at random and blood drawn after an overnight fast and again $2 \mathrm{hr}$ after breakfast for total serum amylase estimation. The meal consisted of cereal; toast or equivalent; bacon, sausage, or egg; plus at least one glass of milk. Subjects were informed of the experimental nature of the study and their consent obtained. The diagnosis of CF had previously been confirmed by abnormal sweat chloride determination (>60 mEq/liter). Fourteen of the CF patients did not have steatorrhea or a history of prolonged diarrhea and did not need pancreatic enzyme replacement therapy. Pancereatic function was therefore considered to be well preserved and this group was analyzed separately. In 13 patients in this group the 5-day fecal fat excretion was less than $10 \%$ intake. In the remaining patient fat excretion was $11 \%$ but pancreatic enzyme output was found to be normal during stimulation by continuous infusion of secretin and cholecystokinin (25). Seven patients had been shown to have a normal elevation of plasma vitamin $\mathrm{A}$ after a standard oral dose. Four patients had had the presence of pancreatic enzymes confirmed by secretin-cholecystokinin infusion, and four had normal quantities of serum pancreatic amylase demonstrated by isoelectric focusing.

A control group of 19 children was obtained from children within the hospital who had no pancreatic or salivary disease. They are listed in Table 1. Also studied were a group of six children with exocrine pancreatic insufficiency and neutropenia (Shwachman's syndrome) (17). Five of the patients had intermittent neutropenia with total neutrophil counts ranging from $30-3268 / \mathrm{ml}$ and one had persistent neutropenia with total neutrophils of $600-1300 / \mathrm{ml}$. Three patients had metaphyseal dysostosis in long bones. All had sweat chloride values within the normal range.

\section{ENZYME ASSAY}

$\alpha$-Amylase activity was determined using starch-iodine reagents following the method of Caraway (6) with some modifications in time and volume of reagents. Nonheparinized blood was assayed for total $\alpha$-amylase from patients and contol subjects immediately after collection. Fifty microliters of serum were incubated with 1 $\mathrm{ml}$ starch substrate at $37^{\circ}$ for $7.5 \mathrm{~min}$. The enzyme-substrate reaction was terminated by the addition of $1 \mathrm{ml}$ iodine solution, Amylase Reagent Set, Harleco, Gibbstown, NJ. Blanks were treated in the same manner without the addition of the enzyme.

For the identification of the $\alpha$-amylase activity in the isoelectric focusing fractions, a volume of $0.5 \mathrm{ml}$ of a dialyzed fraction was incubated with $1 \mathrm{ml}$ starch substrate for $30 \mathrm{~min}$ at $37^{\circ}$. The reaction was then stopped by the addition of $1 \mathrm{ml}$ of the iodine solution. All samples were then made up to a final volume of 10 $\mathrm{ml}$ with distilled water, and the absorbance was measured at 660 $\mathrm{nm}$, with a Gilford spectrophotometer, model 240 (Gilford Instrument Laboratories, Inc., Oberlin, OH).

\section{ISOLECTRIC FOCUSING OF SERUM}

One milliliter of serum was dialyzed overnight against distilled water at $4^{\circ}$. The dialyzed material was centrifuged $(5000 \times \mathrm{g}, 15$ min) and the supernatant which retained the enzyme activity was applied to an isoelectric focusing apparatus as described by Vesterberg and Svensson (23). A jacketed 35-ml capacity $(1 \times 20 \mathrm{~cm})$ column adapted for the Uniphor 7900 column electrophoresis system LKB-Produkter AB, Sweden, was used in all experiments. The concentration of the ampholine carrier (LKB-Produkter AB Sweden) in the $5-50 \%(\mathrm{w} / \mathrm{v})$ sucrose density gradient was $1 \%$ $(\mathrm{w} / \mathrm{v})$. An ampholine carrier gradient of $\mathrm{pH} 4-8$ was prepared from a 1:1 mixture of commercially available ampholine carrier preparations of $\mathrm{pH} 4-6$ and $\mathrm{pH} 5-8$.

The focusing was carried out at $4^{\circ}$ for $48 \mathrm{hr}$ with the initial voltage of $200 \mathrm{~V}$ increasing to a final voltage of $800 \mathrm{~V}$. The anode was placed at the base and the cathode at the top of the column 
Table 1. Diagnosis in control patients

$\begin{array}{lr}\text { Asthma } & 12 \\ \text { Familial dysplasia of lung } & 3 \\ \text { Failure to thrive } & 2 \\ \text { Short gut syndrome } & 1 \\ \text { Chronic neutropenia } & 1\end{array}$

to prevent the fall of higher density anodic focused protein droplets onto the cathodic region of the column (8). The column was eluted in 25-drop fractions at a rate of $40 \mathrm{ml} / \mathrm{hr}$. The $\mathrm{pH}$ value of each fraction was immediately measured with $\mathrm{pH}$ radiometer, type TTTIC, Copenhagen, Denmark. Fractions were then independently dialyzed against tap water at $6^{\circ}$, against distilled water, and,

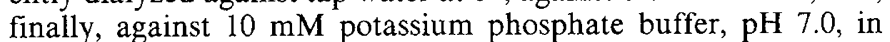
$0.15 \mathrm{M} \mathrm{NaCl}$ at $4^{\circ}$. Dialyzed fractions were finally made up to equal volume of $1.5 \mathrm{ml}$ with the potassium phosphate-saline buffer before enzyme assay.

\section{RESULTS}

Total serum amylase levels (Table 2 ) in all patients were within the expected range quoted for the Caraway method (20-191 $\mu \mathrm{m} / \mathrm{dl})$. When total fasting and postprandial serum $\alpha$-amylase levels are compared between the various groups outlined in Table 2 it is apparent that patients with CF having adequate pancreatic function had higher total $\alpha$-amylase levels than control subjects $(P<0.001)$, CF patients with steatorrhea $(P<0.001)$, and patients with Shwachman's syndrome $(P<0.001)$. There was no difference between total serum amylase levels in control subjects and $\mathrm{CF}$ patients with steatorrhea. Patients with Shwachman's syndrome had significantly lower levels than patients in each of the other three groups $(P<0.001)$. The younger age of the control population was shown to have no effect on the results by two criteria. There was no correlation between age and total serum amylase in either the control $(r=0.13, P=0.6)$ or the CF patients $(r=0.03$, $P=0.8$ ), indicating that serum amylase values did not change with age in the two groups. Total amylase values were also not significantly different among age matched controls, and CF patients with steatorrhea.

Although there was a trend to higher postprandial levels in the control patients a significant postprandial rise of total serum amylase was seen only in patients with Shwachman's syndrome (Table 2). Mean postprandial levels in both groups of patients with $C F$ were slightly lower than fasting levels.

Figure 1 shows a representative amylase isoenzyme pattern for a control patient (Fig. la) and a representative example of a patient with $\mathrm{CF}$ who had no steatorrhea (Fig. 1b). Both show the presence of pancreatic and salivary isoenzymes with the salivary component being of greater magnitude. In Figure $1 d$ the amylase isoenzyme pattern for a patient with $\mathrm{CF}$ without pancreatic function is compared to the pattern seen in a patient with exocrine pancreatic insufficiency and neutropenia (Shwachman's syndrome, Fig. $1 c$ ). It can be seen that only the salivary isoenzyme component of the total amylase is present in both patients and that the pancreatic isoenzyme is missing. Postprandial stimulation failed to evoke a pancreatic isoenzyme component in either case. IEF was performed on sera from 18 patients $(6 \mathrm{CF}$ patients with steatorrhea, $4 \mathrm{CF}$ patients without steatorrhea, 5 patients with Shwachman's syndrome, and 3 normal control subjects). Pre- and postprandial specimens from all groups showed no change from patterns seen in Figures 1 and 2. IEF performed on serum from a CF patient with steatorrhea and a patient with Shwachman's syndrome who showed postprandial elevation of total serum amylase failed to demonstrate any pancreatic isoenzyme.

\section{DISCUSSION}

These results are compatible with the presence of an increased serum salivary amylase isoenzyme activity in patients with $\mathrm{CF}$ regardless of the state of their pancreatic function. In those patients with steatorrhea the serum contained only the salivary isoenzyme (Fig. 1d) yet the total amylase activity was similar to that of a group of control subjects with normal pancreatic function in whom both salivary and pancreatic isoenzymes were present. In those patients with $\mathrm{CF}$ whose pancreatic function was sufficiently intact to promote normal fat absorption, total serum amylase was significantly greater than in either the control patients or the remainder of the $\mathrm{CF}$ patients, at least in part because of an elevated salivary component, inasmuch as the isoenzyme profiles were not different from the normal controls (Fig. 1 $b$ ). In contrast to the CF patients, the patients with Shwachman's syndrome had serum amylase levels significantly lower than the control subjects or CF patients with pancreatic insufficiency, indicating that there was no compensatory increase in the salivary isoenzyme component. Thus the compensatory increase in the salivary isoenzyme activity in serum is not an obligatory feature of pancreatic insufficiency, but is instead a feature of CF.

Direct confirmation of increased salivary isoamylase activity in $\mathrm{CF}$ patients by quantitative estimation of isoenzymes would be desirable but the techniques currently available for isoenzyme separation do not lend themselves easily to accurate measurement. Several attempts to obtain quantitative isoenzyme levels in $\mathrm{CF}$ and related patients have nevertheless been made. O'Donnell et al. (14) employed an inhibitor from wheat with high specificity for the salivary enzyme and concluded that the salivary isoenzyme was moderately elevated in 11 patients with pancreatic insufficiency. Six of these patients had CF. Skude and Erikson (19) and Skude (20) employed agarose gel electrophoresis to separate serum isoenzymes and estimated isoamylase activity by densitometry after incubation of the gels with a dyed starch polymer. With this technique small increases in salivary amylase activity were found in a group of patients with chronic pancreatic insufficiency due to chronic pancreatitis. In contrast marked increases in salivary amylase were reported in four to six patients with CF (19). Thus, two studies provide some evidence of an elevated salivary isoenzyme in CF. Wolf et al. (24), on the other hand, found that CF patients with pancreatic insufficiency had a rather low total serum amylase activity, and they were unable to demonstrate an increase in the salivary amylase component. Isoamylases were measured after separation on polyacrylamide gel electrophoresis by incubating gel slices with starch substrate for up to $48 \mathrm{hr}$. The low total activities may possibly be explained by methodologic factors, inasmuch as patients were apparently not fasted, and as we have shown, differences in total activity may appear postprandially. Interpretation of the isoenzyme results is complicated by the fact that Wolf et al. (24) found serum pancreatic isoamylase activities equal to $30 \%$ of the control values in CF patients with steatorrhea and also were unable to account for $50 \%$ of the serum activity. The high pancreatic isoamylase activity does not conform with our experience or apparently with that of Skude (19), nor is it to be expected in view of the severity of the pancreatic dysfunction.

Both pancreatic and salivary isoenzymes presumably enter the blood stream by regurgitation from glandular cells. Regurgitation is enhanced by resistance to flow (7) and appears to be increased

Table 2. Pre- and postprandial serum amylase activity

\begin{tabular}{lccrr}
\hline & & & \multicolumn{2}{c}{ Serum amylase $^{1}$} \\
\cline { 3 - 5 } & $n$ & Age (yr) & Preprandial & Postprandial \\
\hline Control & 19 & $7.7 \pm 1.3^{2}$ & $73.0 \pm 3.9$ & $78.2 \pm 3.0$ \\
$\begin{array}{c}\text { Cystic fibrosis } \\
\quad \text { With steatorrhea }\end{array}$ & 69 & $11.9-0.7$ & $73.9 \pm 2.4$ & $69.9 \pm 2.6$ \\
$\quad \begin{array}{l}\text { Without steator- } \\
\text { rhea }\end{array}$ & 14 & $12.4 \pm 1.5$ & $115.1 \pm 5.5$ & $104.9 \pm 6.4$ \\
$\begin{array}{c}\text { Schwachman's syn- } \\
\text { drome }\end{array}$ & 6 & $10.5 \pm 2.1$ & $42.6 \pm 2.3$ & $52.5 \pm 4.6^{3}$ \\
& & & & \\
\hline
\end{tabular}

${ }^{1}$ Caraway units (6).

${ }^{2}$ Results expressed as mean $\pm 1 \mathrm{SE}$.

${ }^{3} P<0.01$ for increment using paired $t$-test. 

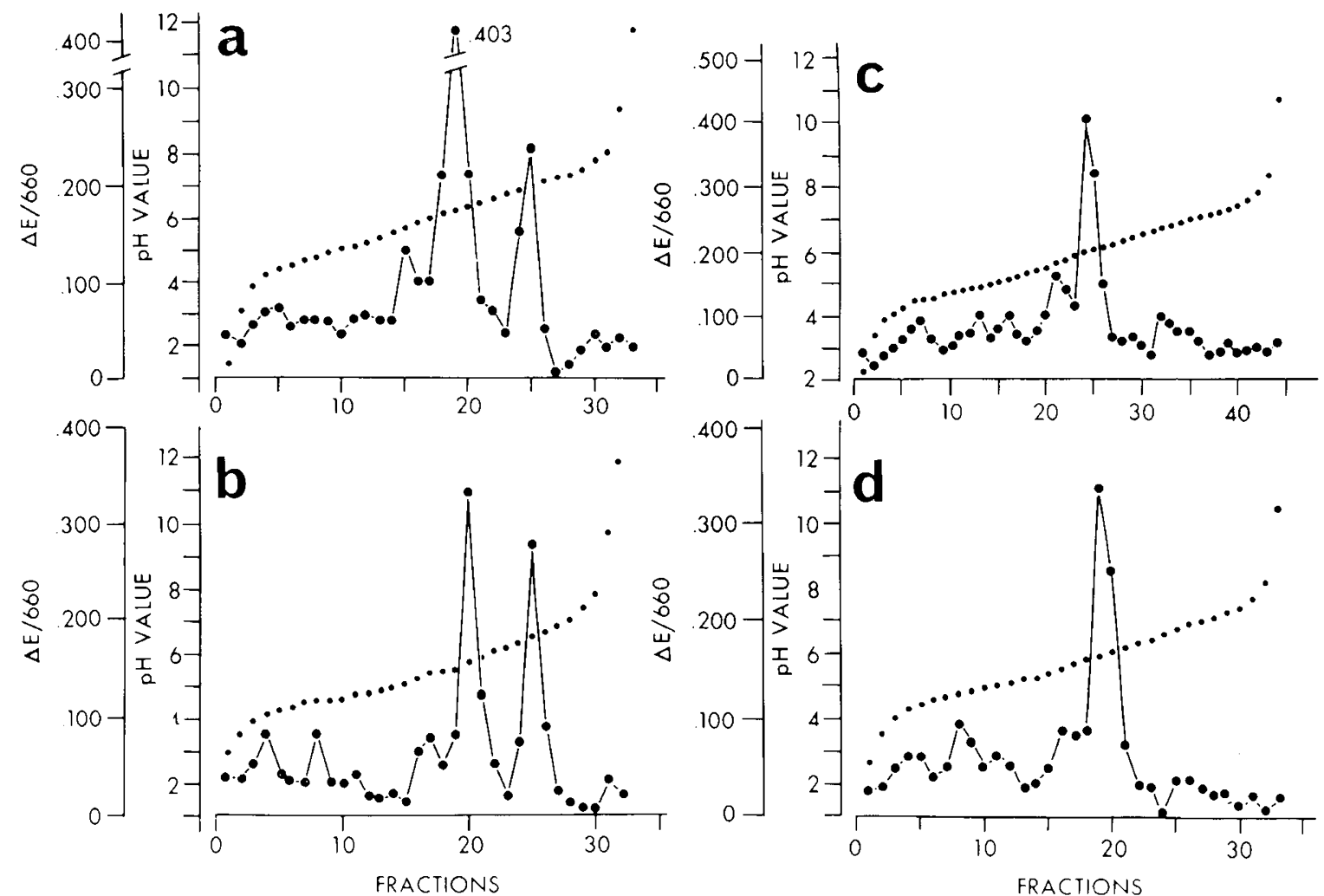

Fig. 1. Isoelectric focusing of representative serum samples from a normal patient (a), a patient with CF and adequate pancreatic function $(b)$, a patient with Shwachman's syndrome $(c)$ and a patient with CF and no pancreatic function $(d)$. In $a$ and $b$ both a salivary (larger peak) and pancreatic peak are present. In $c$ and $d$ only the salivary peak is present.

by secretory stimulation in response to specific secretagogues (9). An enhanced level of salivary amylase activity in patients with CF suggests, therefore, that patients with this disease have either partially obstructed glands, or glands which are stimulated to secrete amylase at an enhanced rate. The evidence suggests that the latter possibility is most likely. Patients with CF have enlarged submaxillary salivary glands with evidence of hyperplasia and hypertrophy $(1,15)$. In addition, many exhibit a slow pupillary response to darkness (16), adrenal medullary hyperplasia (5), and enhanced urinary catecholamine excretion (2), all of which provide evidence for altered autonomic activity which could account for increased salivary secretion. This possibility is supported by the fact that prolonged stimulation with isoproterenol results in salivary gland hyperplasia and hypertrophy in animals (11).

Studies comparing parotid or submaxillary secretory rates and amylase content after stimulation in $\mathrm{CF}$ patients and control subjects have produced conflicting results, showing both high (12) and normal $(3,4,10)$ flow rates and high $(10)$ and not significantly altered $(3,4)$ amylase concentrations in the $C F$ group. Wide variations in salivary response to oral secretogogues appear to be a feature of these studies, making it difficult to produce definite conclusions. It may be that the salivary glands in $\mathrm{CF}$ patients are already maximally stimulated and unable to respond to further stimulation. The fact that neither group of $\mathrm{CF}$ patients exhibited a rise in total serum amylase postprandially supports this conclusion, and suggests further that salivary flow was relatively unimpeded.

Failure to demonstrate increased levels in the patients with pancreatic function is rather surprising since these patients appear to have an increased susceptibility to recurrent attacks of pancreatitis (18), and might be expected to have an enhanced response to the provocation of a meal. None of the patients in our series had a history of pancreatitis, however, and presumably at the time of sampling pancreatic flow was relatively unobstructed.

The behavior of the patients with CF was in marked contrast to the behavior of patients with Shwachman's syndrome, whose amylase levels postprandially rose significantly from a relatively low base. Inasmuch as the salivary isoenzyme concentration in the patients with Shwachman's syndrome was not elevated in the fasting state, these patients exhibited no evidence of chronically increased secretory stimulation. The postprandial response suggests, however, that they are capable of a vigorous secretory response to food. Thus, there seems to be no impairment in the regulation of secretion such as is found in $\mathrm{CF}$, although the possibility cannot be excluded that some degree of outflow obstruction exists.

\section{REFERENCES AND NOTES}

1. Barbero, G. J., and Sibinga, M. S.: Enlargement of the submaxillary salivary glands in cystic fibrosis. Pediatrics, 29: 788 (1962).

2. Barbero, G. J., and Braddock, L. I.: Elevated levels of free urinary catecholamines in cystic fibrosis, Cystic Fibrosis Club Conference Abstracts, 1967, p. 4.

3. Blomfield, J., Allars, H. M., Rush, A. R., van Lennep, E. W., and Brown, J. M.: Parotid serous hypersecretion in cystic fibrosis. Aust. Paediat. J., 10: 75 (1974).

4. Blomfield, J., Rush, A. R., Allars, H. M., and Brown, J. M.: Parotid gland function in children with cystic fibrosis and child control subjects. Pediat. Res., 6: 574 (1976).

5. Bongiovanni, A. M., Yakovac, W. C., and Steikder, D. D.: Study of adrenal glands in childhood: Hormonal content correlated with morphologic characteristics. Lab. Invest., 10: 1956 (1961).

6. Caraway, W. T.: A stable starch substrate for the determination of amylase in serum and other body fluids. Amer. J. Clin. Pathol., 32: 97 (1959).

7. Gibbs, G. E., and Ivy, A. C.: Early histological changes following obstruction of pancreatic ducts in dogs: correlation with serum amylase. Proc. Soc. Exp. Biol. Med., 77: 251 (1951).

8. Haglund, $\mathrm{H}$.: Isoelectric focusing in $\mathrm{pH}$ gradients: A technique for fractionation and characterization of ampholytes. Methods Biochem. Anal., 19: 1 (1971).

9. Janowitz, H. D., and Dreiling, D. A.: The plasma amylase. Source regulation and diagnostic significance. Amer. J. Med., 27: 924 (1959).

10. Mandel, I. D., Kutscher, A., Denning, C. R., Thompson, R. H., and Zagarelli, E. V.: Salivary studies in cystic fibrosis. Amer. J. Dis. Child., 113: 431 (1967),

11. Mangos, J. A.: Studies on the pathogenesis of cystic fibrosis: The isoproterenol treated rat as an experimental model. In: Proceedings of the Fifth International Cystic Fibrosis Conference, p. 23, 1967.

12. Marmar, J., Barbero, G. J., and Sibinga, M. S.: The pattern of parotid gland secretion in cystic fibrosis of the pancreas. Gastroenterology, 50: 551 (1966).

13. Nikolajec, W. P., and Emrich, H. M.: $\alpha$-amylase activity in sweat serum of 
patients with cystic fibrosis of the pancreas. Europ. J. Pediat.. 122: 289 (1976).

14. ODonnell, M. D., Fitzgerald, O., and McGeerry, K. F.: Differential serum amylase determination by use of an inhibitor, and design of a routine procedure. Clin. Chem., 23: 560 (1973).

15. Roy, C. C., Silvermen, A., and Cozzetto, F. J. (eds.): Pediatric Clinical Gastroenterology, p. 617 (C. V. Mosby Co., St. Louis, 1975).

16. Rubin, L. S., Barbero, G. J., and Chernick, W. S.: Pupillary dysfunction as a concomitant of cystic fibrosis. Pediatrics, 38: 865 (1966).

17. Shwachman, H., Diamond, L. K., Oski, F. A., and Khaw, K.-T.: The syndrome of pancreatic insufficiency and bone marrow dysfunction. J. Pediat., 65: 645 (1964).

18. Shwachman, H., Leventhal, E., and Khaw, K.-T.: Recurrent acute pancreatitis in patients with cystic fibrosis with normal pancreatic enzymes. Pediatrics, 55: 86 (1975).

19. Skude, G.: Sources of the serum isoamylases and their normal range of variation with age. Scand. J. Gastroenterol., 10: 577 (1975).

20. Skude, G., and Erikson, S.: Serum isoamylases in chronic pancreatitis. Scand. J. Gastroenterol., 11: 525 (1976).

21. Sun, D. C. H.: The use of pancreozymin-secretin test in the diagnosis of pancreatitis and tumors of the pancreas. Gastroenterology, 45: 203 (1963).

22. Taussig, L. M., Wolf, R., Wood, R. E., and Deckelbaum, R. J.: Use of serum amylase isoenzymes in evaluation of pancreatic function. Pediatrics, 54: 229 (1974).

23. Vesterberg, O., and Svensson, H.: Isoelectric fractionation analysis and characterization of ampholytes in natural $\mathrm{pH}$ gradients. Acta Chem. Scand., 20:820 (1966).

24. Wolf, R., Taussig, L., Ross, M., and Wood, R.: Quantitative evaluation of serum pancreatic isoamylases in cystic fibrosis. J. Lab. Clin. Med., 87: 164 (1976).

25. Wormsley, K. G.: The response to infusion of a combination of secretin and pancreozymin in health and disease. Scand. J. Gastroenterol., 4: 623 (1969).

26. We thank Dr. D. Crozier for allowing us to study patients under his care and Dr. F. Morad Hassell and staff of the Cystic Fibrosis Clinic at The Hospital for Sick Children for their assistance.

27. Requests for reprints should be addressed to: Dr. G. G. Forstner, Kinsmen Cystic Fibrosis Research Center, The Hospital for Sick Children, Toronto, Ontario M5G IX8 (Canada).

28. Received for publication August 12, 1977.

29. Accepted for publication January 5. 1978. 